\title{
Contribuições do acompanhamento terapêutico na assistência ao portador de transtorno mental
}

\section{Contributions of therapeutic follow-up in care for patients with mental disorders}

\section{Contribuciones del acompañamiento terapéutico en la atención al portador de trastorno mental}

Aline Cristina Dadalte Carniel', Luiz J orge Pedrão"

\author{
' Psicóloga. Mestre em Enfermagem Psiquiátrica. Psicóloga do Hospital Espírita Vicente de Paulo. Ribeirão Preto, SP. E-mail: \\ alinedadalte@ig.com.br. \\ "Enfermeiro. Doutor em Enfermagem. Professor Doutor da Escola de Enfermagem de Ribeirão Preto da Universidade de São Paulo. E-mail: \\ lujope@eerp.usp.br.
}

\section{RESUMO}

A reforma psiquiátrica possibilitou transformações na assistência à saúde mental e o acompanhamento terapêutico (AT) faz parte dessas transformações. Vem fundamentando suas bases teóricas e sua prática aceita cada vez mais, por preencher as lacunas deixadas pelos tratamentos psiquiátricos tradicionais. O presente estudo objetivou apontar e discutir a contribuição do acompanhamento terapêutico no processo de assistência e reabilitação psicossocial do portador de transtorno mental. Para tanto foi escolhida, junto a uma equipe multiprofissional de um Centro de Atenção Psicossocial de Ribeirão Preto-SP, em 2007, uma usuária com a qual foram realizados dezesseis encontros de AT, cujos conteúdos foram trabalhados segundo o método qualitativo. Os resultados mostraram uma contribuição muito positiva do AT, tais como: resgate da auto-estima; retomada da realização de atividades rotineiras; convívio mais saudável no meio familiar e social e criação de momentos de confronto do estado mental com a realidade, possibilitando modificações no comportamento e melhoria da qualidade de vida. Assim sendo, foi possível considerar que o AT constitui-se em mais uma modalidade terapêutica a contribuir para a assistência e reabilitação psicossocial do portador de transtorno mental e pode ser incluído nos planos terapêuticos dos serviços de assistência à saúde mental, inseridos no contexto da reforma psiquiátrica.

Descritores: Acompanhantes de pacientes; Terapias alternativas; Enfermagem psiquiátrica.

\section{ABSTRACT}

The psychiatric reform allowed for transformations in mental health care and therapeutic accompaniment (TA) is part of these transformations. Its theoretical bases are increasingly solid and its practice accepted because it fills the gaps left by traditional psychiatric treatments. This study aimed to point and to discuss the contribution of TA in psychosocial care and rehabilitation of patients with mental disorders. Therefore, a multi-professional team from a Psychosocial Care Center of Ribeirão Preto-SP, in 2007, chose one female user, with whom sixteen TA meetings were held. The contents of these meetings were analyzed by means of the qualitative method. Results showed a very positive contribution of TA, such as: recovery of self esteem and daily activities; healthier experiences in family and social life and the creation of moments of confrontation between the mental state and reality, which allowed behavioral modification and improved quality of life. Thus, it could be considered that TA is another treatment mode to contribute to psychosocial care and rehabilitation of patients with mental disorder and can be included in therapeutic planning of mental health services and care, inserted in the psychiatric reform context.

Descriptors: Patiente escort service; Alternative therapies; Psychiatric nursing.

\section{RESUMEN}

La reforma psiquiátrica posibilitó transformaciones en la atención a la salud mental y el acompañamiento terapéutico (AT) hace parte de esas transformaciones. Viene fundamentando sus bases teóricas y su práctica aceptada cada vez más, por llenar las lagunas dejadas por los tratamientos psiquiátricos tradicionales. La finalidad de este estudio fue señalar y analizar la contribución del AT en la atención y rehabilitación psicosocial del portador de trastorno mental y, para eso, fue elegida, junto a un equipo multi-profesional de un Centro de Atención Psicosocial de Ribeirão Preto-SP, en 2007, una usuaria con la cual fueron realizados dieciséis encuentros de AT, cuyos contenidos fueron trabajados según el método cualitativo. Los resultados mostraron una contribución muy positiva del AT, tales como: rescate de la auto-estima; retomada de la realización de actividades rutineras; convivio más salubre en el medio familiar y social y creación de momentos de confronto del estado mental con la realidad, posibilitando modificaciones en el comportamiento y mejoría de la calidad de vida. Así, fue posible considerar que el AT constituye otra modalidad terapéutica a contribuir para la atención y rehabilitación psicosocial del portador de trastorno mental y puede ser incluido en los planes terapéuticos de los servicios de atención a la salud mental, insertados en el contexto de la reforma psiquiátrica.

Descriptores: Acompañantes de pacientes; Terapias alternativas; Enfermería psiquiátrica. 


\section{NTRODUÇÃO}

O Acompanhamento Terapêutico (AT) é uma clínica que se desenvolve nos mais diferentes lugares e contextos, ocorrendo no cotidiano, como um recurso de vanguarda, pois está atuando no espaço de articulação profissional, familiar e social ${ }^{(1)}$. É uma modalidade que estabelece normas, tais como: tempo; espaço; perspectivas; honorários e habilidades pessoais. A prática não se restringe apenas à saúde mental, e atua principalmente na residência, onde o objetivo é a reorganização do espaço e das relações afetivo-familiares da pessoa em questão(2).

O AT é modalidade terapêutica usada em meio ao processo de reabilitação psicossocial, resgatando vínculos sociais, sua cidadania e sua circulação em espaços físicos e sociais, que façam sentido para o portador, independente de sua patologia. A reabilitação psicossocial é vista como processo fundamental de remoção de barreiras que impeçam a interação da pessoa com a comunidade e o pleno exercício de seus direitos de cidadania ${ }^{(3)}$.

A reabilitação extrapola a especificidade das profissões de saúde, cujas ações têm pontos de inserção que abrem possibilidades para criatividade do agir, que se relacionam as habilidades e capacidades, tanto dos profissionais como do usuário inserido na assistência em saúde mental. Leva à reflexão contínua de que não há limite definido para este processo de buscar de ações que não estejam dentro de um protocolo organizado academicamente para produzirem reabilitados ${ }^{(4)}$.

O AT é prática estratégica da anti-segregação, que resgata a capacidade de inclusão social, oferece a possibilidade de se prevenir a cronificação, a institucionalização e a alienação social ${ }^{(5)}$. 0 profissional presta o serviço no momento mais difícil, onde poderá decidir pelo cliente em situações nas quais este ainda não é capaz de agir por si só. Empresta o ego a ele em determinados momentos, e, espelho dos seus aspectos mais neuróticos, ajuda a conseguir uma linguagem libertadora, permitindo-o sair de sua clausura para reintegrar-se a sociedade. O acompanhante terapêutico (AT) deve estimular o desenvolvimento das áreas mais organizadas daquela personalidade neurótica propondo tarefas interessantes, canalizando as inquietudes para liberar a capacidade criativa inibida, a estruturação da personalidade e ajudar a reencontrar-se com a realidade. O AT deve, ainda, dissociar-se para poder relacionar-se com o cliente e ao mesmo tempo manter um distanciamento que lhe permita observar e avaliar a interação com ele $e^{(6)}$.

A família, grupo primário e natural participa no desenvolvimento humano, no que se refere às características sociais, éticas, morais e cívicas do indivíduo. É no seio familiar que o ser humano tem a capacidade de desenvolver laços afetivos mais profundos $^{(7)}$. As famílias disfuncionais desenvolvem problemas porque não são capazes de ajustarem-se às transições que ocorrem no ciclo vital familiar, tornam-se rígidas e cristalizadas em alguns aspectos. O problema não é apenas o doente, mas a maneira que a família reage, interage e tenta adaptar-se ao período de crise $^{(8)}$.

Por isso é de importante valor diagnóstico registrar as mudanças observadas no cliente em relação ao vínculo com a família, o tipo de pessoas com quem se relaciona, perceber mudanças no sono, alimentação, higiene pessoal, ou seja, nos vínculos significativos para ele.

O AT poderá ocorrer em qualquer ambiente, como na rua, na própria residência do cliente e outros. Escutar, prestar atenção na vida do outro, compartilhar a experiência de cada um e ajudar a restabelecer pontes com 0 mundo, são fatores básicos. Usar a criatividade e estratégias que ajudem o cliente a ganhar consistência numa situação de encontro. $O$ encontro é extemporâneo, não estruturado, não planejado, sem ensaios - produz-se no momento, no aqui e agora. A primeira fase é chamada de aquecimento, onde acontece a preparação do encontro, a segunda fase a dramatização, o ato do encontro paciente/terapeuta e paciente/consigo mesmo, a terceira, a fase dos comentários, das análises e do compartilhar ${ }^{(9)}$.

O AT caminha com as idéias do encontro, com troca com o portador de transtorno mental, onde se vive e experimenta situações do passado, de hoje e do futuro, no aqui e agora, ocorrendo reciprocidade total, um encontro de corpos onde possam se tocar e comunicar-se de forma simples. O AT é também cuidador e a prática do cuidar se dá pela atenção, preocupação, responsabilidade, observação, afeto, amor e simpatia pelo outro; ajudando, compreendendo, aceitando e respeitando o conhecimento do outro. Na relação de estar com a pessoa, ambos são participantes de um processo de aprendizagem e descoberta, conhecendo o outro com seus limites, dificuldades e necessidades. $O$ cuidador precisa ter paciência, tolerância, honestidade, confiança, humildade, aceitação, esperança e desafio ${ }^{(10)}$.

A relação de ajuda abrange vários tipos de relações: com a pessoa e sua família, médico, professores, terapeutas e outros ${ }^{(11)}$. O AT caminha nessa mesma direção: utilizar de forma funcional os recursos internos latentes do indivíduo.O AT é, por si só, um ato de movimento e de deslocamento do corpo do terapeuta até o corpo do acompanhado, este trabalho é uma prática que em si já se constitui investida no corpo do sujeito, portanto corporal, impressa na marca dos movimentos do corpo já no próprio ato de acompanhar ${ }^{(5)}$.

O AT, enquanto modalidade terapêutica assistencial não tradicional em saúde mental vem 
ampliando seus conceitos e fundamentando suas bases teóricas. Sua valorização ao preencher as lacunas que os tratamentos psiquiátricos tradicionais deixam, devido aos seus limites, aumenta sua aceitação pelos diferentes profissionais, principalmente depois que as portas dos manicômios foram definitivamente abertas.

Acreditando ser possível associar modalidades terapêuticas não tradicionais na assistência ao portador de transtornos mentais, o AT pode contribuir muito na reinserção desse portador na sociedade, através do processo de reabilitação psicossocial, sustentando também a manutenção de seu estado de equilíbrio, modificando o comportamento e resgatando a qualidade de vida, aspectos esses dificilmente conseguidos apenas pela ação dos "remédios".

Assim sendo, a justificativa para a realização desta pesquisa se ampara na possibilidade de focalizarmos essa prática por meio do método científico. Considerando a importância das transformações que vêm ocorrendo na assistência psiquiátrica em favor do acolhimento do portador de transtorno mental, este trabalho pretende, ao apontar os benefícios da prática do AT por meio da observação e análise de um caso concreto, mostrar as possibilidades de inclusão da prática do AT nos projetos terapêuticos das instituições que assistem essa clientela.

Por isso, o presente estudo teve como objetivo apontar e discutir a contribuição do AT no processo de assistência e reabilitação psicossocial do portador de transtorno mental.

\section{MÉTODO}

Trata-se de uma pesquisa qualitativa descritiva que aborda a prática do AT fundamentada em diversos autores e estudos relacionados, analisando os benefícios do AT dentro de um projeto terapêutico multiprofissional, focando a relação entre o AT e o portador de transtorno mental e a importância desse encontro.

Participou deste estudo uma portadora de transtorno mental, acompanhada em regime semiintensivo no Centro de Atenção Psicossocial (CAPS) da Secretaria Municipal da Saúde da Prefeitura Municipal de Ribeirão Preto/SP, Brasil, que possui três modalidades de assistência psiquiátrica: cuidado intensivo, semi-intensivo e não-intensivo. A usuária estava no programa de cuidado semi-intensivo, e os critérios para a escolha da instituição foram: o grau de abertura da equipe para o trabalho, o enfoque multidisciplinar dos atendimentos e atividades realizadas; o acesso aos dados do sujeito da pesquisa e o interesse por parte da equipe multiprofissional em manter um grupo de discussão e articulação permanente com a pesquisadora. A pesquisa de campo foi realizada no ano de 2007.
A usuária participante do estudo (denominada, aqui, Lua) foi escolhida pela equipe do CAPS, por apresentar o seguinte quadro: diagnóstico de depressão moderada, transtorno de alimentação, transtorno bipolar, transtorno de personalidade narcisista, transtorno conversivo e bulimia, desencadeados após um acidente de carro ocorrido há 12 anos, no qual perdeu 90\% da visão, passando a enxergar apenas vultos.

O motivo de sua escolha pela equipe referida foi sua limitação e a não aceitação da condição (deficiente visual), situação que indicava que o AT trabalharia favoravelmente no alívio de seu sofrimento psíquico e também no enfrentamento de suas limitações físicas e psíquicas, buscando melhor qualidade de vida. A usuária morava com o avô e a mãe, a qual, por ser portadora de síndrome do pânico, também fazia parte do programa de assistência do CAPS.

Lua passava a maior parte do tempo em casa, dormindo, e não demonstrava interesse por nada. Deveria ir ao CAPS para atividades programadas, mas comparecia apenas na avaliação do psiquiatra, não se interessando pelos outros atendimentos.

Fato relevante foi o acidente que tornou Lua deficiente visual ter ocorrido seis meses antes de ela concluir o curso de musicoterapia. Após o acidente, voltou a estudar concluindo tal curso, teve uma vida social, com amigos e família, saía com os amigos para se divertir e a família sempre a apoiou em tudo que precisasse. Com o passar do tempo, Lua foi se afastando dos amigos, se isolando, perdendo o interesse por tudo. Atualmente, com 32 anos de idade, está obesa, não tem vontade de sair de casa, desenvolveu alguns transtornos, tem muita ansiedade e apresenta obesidade mórbida.

O projeto foi submetido ao Comitê de Ética em Pesquisa Envolvendo Seres Humanos da Escola de Enfermagem de Ribeirão Preto da Universidade de São Paulo (protocolo no 0652/2006). Após isso, a pesquisadora participou de diversas reuniões da equipe multiprofissional para discussões de casos de portadores de transtornos mentais em regime semiintensivo no CAPS, onde foi escolhida a usuária para ser assistida também através da prática do AT.

Escolhida a usuária, essa foi informada de todo o processo do AT e também a proposta de se submeter a este tipo de assistência. Após as informações, e com o seu aceite para o enquadramento nesta modalidade terapêutica, ela assinou o Termo de Consentimento Livre e Esclarecido juntamente com um familiar responsável (avô) e foi feito, junto com ela, todo um plano de trabalho a ser desenvolvido, que constou de 16 encontros de acompanhamento terapêutico, uma vez por semana, o que traduziu em um tempo de assistência de quatro meses.

Os encontros foram desenvolvidos nos seguintes locais: no CAPS, em restaurantes, dentro da própria 
residência, palestra informativa e Associação de Apoio aos Psicóticos (AAPSI), tiveram duração média de uma hora e trinta minutos e foram rigorosamente observados pelo próprio AT (observação participante).

Cada encontro foi arquivado para posterior análise. Os comportamentos considerados importantes apresentados pela usuária nos encontros, inclusive as suas falas, foram anotados em um diário de campo, para auxiliar na elaboração de um registro geral (relatório) que foi realizado pelo próprio AT no final de cada encontro. Foram analisados aspectos relativos à sua assistência e reabilitação psicossocial, tais como: resgate de sua auto-estima; retomada de realização de atividades que fazia anteriormente ao início dos sintomas de seu transtorno mental; motivação para novamente buscar o laser e conviver de forma mais saudável no seu meio familiar e social; criação de momentos de confronto de seu estado mental com a realidade, possibilitando modificações no comportamento e melhoria da qualidade de vida(12).

Os resultados, portanto, foram analisados pelo método de análise de conteúdo dos encontros de AT realizados, utilizando a modalidade de análise temática, onde o tema está ligado a respeito de um determinado assunto, comportando um feixe de relações apresentadas graficamente por uma palavra, uma frase ou um resumo, visando o descobrimento dos núcleos de sentido, que compõem uma comunicação cuja presença ou freqüência signifiquem alguma coisa para o objetivo ${ }^{(12)}$.

Assim sendo, a síntese elaborada foi examinada por três examinadores, sendo dois com formação básica na Área de Ciências Humanas, com grande aproximação à área específica em questão, ou seja, a Área da Saúde Mental, e, o terceiro, também com formação básica na Área de Ciências Humanas, mas sem nenhuma aproximação com a Área da Saúde Mental. Esses examinadores, individualmente, após os exames das sínteses dos dezesseis encontros, fizeram uma nova síntese, mas agora, estabelecendo todo o significado de cada um dos encontros, em apenas uma frase. Sequencialmente, em uma reunião, foram feitas as leituras das frases dos três examinadores e realizada uma profunda discussão, para, finalmente, através do consenso, serem estabelecidas as dezesseis frases representativas dos dezesseis encontros.

Desta forma, os resultados são apresentados de maneira descritiva, mostrando as sínteses de cada encontro de forma real, utilizando-se às próprias falas de Lua e do at, e a frase representativa de cada um deles, discutidos de forma qualitativa descritiva a partir de suas sínteses, com breve comentário ao final de cada encontro, buscando uma articulação com a realidade descrita. No final da apresentação das sínteses, frases e comentários, é apresentada uma discussão geral, e, posteriormente, as considerações finais.

\section{APRESENTAÇÃO E DISCUSSÃO DOS RESULTADOS}

No primeiro encontro, Lua chegou atrasada ao CAPS acompanhada da mãe. Fomos apresentadas pelo enfermeiro e, então foi falado sobre a proposta do AT e firmado o contrato. Os encontros seriam uma vez por semana num total de 16 a 20, e poderiam ser, no início, em locais de sua preferência, como" sua casa, por exemplo, e no próprio CAPS. Posteriormente, a proposta era sair destes locais, e, com o tempo, realizá-los nos mais variados lugares, em praças, na rua, no cinema, onde houvesse necessidade e/ou interesse. Disse que o intuito do trabalho era de ressocialização, interação, melhora na qualidade de vida, mudança do cotidiano e do comportamento. Expliquei que o trabalho do AT, apesar de criar fortes vínculos afetivos, não deixava de ser um trabalho profissional, realizado em equipe multidisciplinar, essa formada por mim em conjunto com os profissionais do CAPS. A frase representativa deste primeiro encontro foi a seguinte: 0 contrato visando uma melhora na qualidade de vida.

Um contrato firmado, mesmo que apenas verbalmente, implicitamente, é um criador de bases limítrofes para a relação acompanhante-usuária. Ele firma um compromisso que implica em direitos e deveres, imputa responsabilidades às partes nesta busca em conjunto pela melhora da qualidade de vida. No caso do AT isso é importante devido, talvez, ao fato da metodologia dessa forma de tratamento (a falta de um lócus definido, sala, consultório, horário, e todo um sistema ao qual estamos culturalmente habituados) poder causar uma falsa impressão de que não se trata de um trabalho e sim lazer.

Nesta proposta, acompanhado e acompanhante não estão em uma sala de consultório ou em uma instituição, mas sim, assistindo televisão ou filme no cinema, batendo papo em um bar ou no quarto da pessoa, ou ainda com seus familiares, ou seja, habita-se e transita-se pelo espaço público e privado $^{(6)}$.

No segundo encontro, proposto para a casa de Lua, quando cheguei me deparei com um lugar escuro, úmido, sujo, com cheiro nauseante. Lua tinha três cachorros, e eles faziam suas necessidades pela casa toda, inclusive em cima do sofá e das camas. Ao entrar no quarto a sensação de mal-estar era ainda pior, pedi para que ela abrisse um pouco a janela ao que ela respondeu: "não gosto de sol e claridade, prefiro ficar no escuro, vou acender a luz, pode ser?".

Propus fazer uma leitura de um livro de poesia de Carlos Drummond de Andrade, ela aceitou e depois da leitura aprovou, achando todas "lindas, especialmente uma delas" a qual reli. Lua se emocionou refletindo sobre há quanto tempo ela não 
lia. "Tenho saudades". Mencionei que ela poderia aprender a ler em Braile, e ela se incomodou. A frase representativa deste encontro foi: O AT reavivando um sentimento de prazer.

Quando, logo no início da relação, o at consegue resgatar um sentimento prazeroso da usuária cria-se uma esperança para essa, ainda que inconsciente, da possibilidade de alcançarem aquele objetivo. A relação começa a se amarrar de forma construtiva, proporcionando um prazer que a usuária há tempo não experimentava. Nem sempre é possível uma interação como essa, que vislumbrava contentamento e mexia com conceitos pré-formados da usuária logo no início do tratamento.

No terceiro encontro, estávamos no quarto de Lua quando a mãe entrou e perguntou se ela havia me dito quantos anos tinha. "Sim, quando nos conhecemos", mas, segundo a mãe, a idade de Lua havia mudado. "Quantos anos você tem, filha?" perguntou a mãe. Com uma voz forçadamente infantilizada respondeu: "Quatro aninhos".

Ouvíamos um CD que estava quase no fim quando ela pediu que eu desligasse o aparelho. Estava confusa, a música a deixava confusa, não sabia se tinha "três ou trinta e um anos", confundindo mais ainda as idades.

Perguntei qual idade ela preferia ter. "Não sei", respondeu. Pedi que refletisse sobre isso. O que ela fazia quando tinha três anos? "Brincava". Que mais? "Só!" E com trinta e um? "Nada! Só fico no quarto e na cozinha, comendo".

A confusão era grande, Lua queria que eu fosse embora, eu estava "atrapalhando" a vida dela. Representa este encontro a frase: Lua não sabia se tinha três ou 31 anos.

O AT conseguiu causar na usuária o enfrentamento da despersonalização que ela apresentava ao afirmar ter quatro ou três anos de idade, ao atentar para detalhes do cotidiano que desmentiam aquela idade. A idade do cachorro, a forma física da usuária, a música da qual ela gostava.

No quarto encontro, ainda na casa de Lua ela dizia: "Tem uma bruxa falando comigo. Eu mando ela ir embora, mas ela fica na minha cabeça". "E o que é que a bruxa diz?", perguntei. Explicou que a bruxa dizia que aquela casa era amaldiçoada e ela, Lua, deveria "colocar fogo na casa". "E o que você acha disso?", perguntei. Lua achava errado. A bruxa só dava idéias de coisas erradas e ruins, atormentandoa. "Ela fala que eu sou feia e chata, e que minha vida é uma chatice". "E o que você acha sobre sua vida?", perguntei. "Acho que é isso mesmo", respondeu. "E essa bruxa, o que você acha?", indaguei. "É feia e chata!", foi a resposta.

Neste encontro Lua manifestou uma figura para exteriorizar o que achava de si e do meio em que ela vivia. Tentei fazer com que ela atentasse ao fato de que as opiniões daquela bruxa eram as mesmas dela.
A despersonalização de si mesma ficou marcante nesse encontro, onde Lua descreveu exatamente como se via, porém, em um primeiro momento não tinha consciência. Por àquela hora achei o suficiente.

Antes do quinto encontro houve um telefonema, onde Lua disse o seguinte: "Fui ao médico e, chegando lá, ele me colocou de frente ao espelho e perguntou o que eu via. Disse a ele que via uma pessoa gorda, feia, chata, triste, que levava uma vida muito chata. Era uma bruxa. Então descobri que eu sou a bruxa e não quero ser assim". Lua insistiu: "Acho que quero mudar a minha vida, não quero ser assim". Desta forma, incluindo o telefonema, a frase representativa do quarto encontro foi: Assumindo a visão de si mesma. Querer mudar. Assim, Lua toma consciência do que representava para ela a sua condição, o que pode ser entendido como o início do processo de mudança.

Em todo ser humano existe um processo natural e permanente de desenvolvimento, onde sempre se busca auto-realização, autonomia e ajustamento, quando isso não acontece, criamos condições favoráveis para que ele liberte-se para o desenvolvimento, identificando e retirando os obstáculos que o estão impedindo de $\operatorname{crescer}^{(13)}$.

No quinto encontro, Lua comenta: "Antes do acidente trabalhei num 0300, um disque sexo e amizade. Meu avô não sabia, eu adorava conversar com as pessoas, tinha muita lábia, boa de conversa, após o acidente desanimei. Eu tinha um namorado, mas também terminamos e ele sumiu como todos, e eu fiquei aqui com essa vida chata, monótona, eu e minha mãe nessa simbiose louca... Preciso mudar minha vida e estou disposta".

Lua comentou querer passar por uma cirurgia no estômago para emagrecer. "Me sinto muito cansada, com os pés inchados, não consigo caminhar, é muito ruim", afirma. Assim, a frase representativa deste encontro foi a seguinte: Reflexões e vontades em direção ao real.

Uma ferramenta fundamental do trabalho do at é a escuta. O escutar do terapeuta permite ao paciente falar e ser reconhecido, como também permite ao terapeuta compreender a mensagem, pois escutar não é sinônimo de ficar em silêncio ${ }^{(14)}$.

No sexto encontro, ainda na casa de Lua, ela dizia: "Estou muito infeliz, não tenho vontade de fazer nada, sei que preciso me levantar, fazer algo, mas não consigo. Não vejo alternativa pro meu problema", afirmou. Ela pediu para que eu abrisse uma das portas do guarda-roupa para ver sua coleção de All Star. Havia vários, de todas as cores. Eram a paixão dela, disse, não via a hora de usá-los novamente, as roupas também. Sempre foi muito vaidosa, tinha um "corpão violão de parar o trânsito". Lua lembra que tinha uma vida muito ativa e agora estava ali, vendo a vida passar lentamente, sem 
motivação. Então, a frase representativa deste encontro foi: Mudar implica superação.

Lua mostrou-se um tanto desanimada, porém era notável que a vontade de melhorar sua vida era grande, resgatar prazeres antigos, mas o mudar requer sacrifícios e esforços para superar os desafios vislumbrados, como a inadequação dela aos tratamentos e a falta de empatia ideológica com alguns dos profissionais e as deficiências do sistema. A motivação devia ser o mote do at. Mostrar que não é impossível, mas difícil sabendo que haveriam momentos de recaída.

O AT, nesse encontro, teve papel importante como mediador das vontades de Lua, cuidando para que essas não ficassem na esfera das falsas esperanças, criando fantasias.

Relativo à transformação de alguém, o melhor não é pressioná-lo na direção da mudança, nem mesmo ensinar-lhe o caminho a seguir ou guiá-lo pela inteligência, mas sim, aceitar, dando valor aos seus receios, às suas angústias, às resistências e a tudo aquilo que o impede de mudar ${ }^{(15)}$.

O sétimo encontro ainda ocorre na casa de Lua. Refletimos juntas sobre momentos difíceis da vida pelos quais passamos e que há momentos felizes também, às vezes nossa vida fica marcada por uma situação muito difícil e consideramos esta situação um marco depois do qual tudo parece ruim, mas somos nós mesmos que criamos essa situação deixando de perceber que ainda acontecem coisas boas, independentes da situação em que nos encontramos, e que o importante não é o que fizeram conosco, mas sim, o que nós iremos fazer do que fizeram de nós. O que vamos fazer dali pra frente. "Pense sobre isso", pedi. E propus sairmos no próximo encontro, Lua falou que estava querendo ir a um bar de espetinhos ali, perto de sua casa, já há algum tempo, mas não tinha coragem.

“Então, essa é a oportunidade perfeita para começarmos a enfrentar essa situação", comentei. Ela topou e chamou a mãe pra ver se não queria ir junto. A mãe achou ótima idéia, combinamos para a próxima semana, eu ligaria para confirmar a hora e o lugar. A frase representativa do encontro foi: A emoção como combustível para a razão.

Nos momentos de crise, podemos encará-la como um beco sem saída ou como oportunidade de criar novas possibilidades. A emoção pode cegar a razão ou tornar-se o combustível que a põe em movimento. Daí vem o ânimo para racionalizar o enfrentamento dos desafios, desde os aparentemente mais simples como ir a um bar de espetinhos.

Estimular a pessoa a criar, ou seja, a usar a criatividade é importante, pois facilita o seu retorno ao mundo real, ao reencontro com sua vitalidade e assim a criatividade promove o sentimento de estar $\operatorname{vivo}^{(6)}$.
No oitavo encontro, o primeiro proposto para ser fora da casa de Lua, ela estava toda arrumada, com uma linda faixa na cabeça, brincos, batom cor-derosa e fui logo elogiando o perfume muito bom e os acessórios. Era notória a felicidade do avô e da mãe por verem Lua toda arrumada. A mãe, que também se embelezara aparentava ansiedade e foi chamando: "então vamos". Fomos juntas no mesmo carro.

"Tô muito nervosa, não consigo nem sair do carro direito", ela disse.

"Calma, se você se acalmar consegue sair daí e vamos pegar uma mesa boa", falei. Lua se acalmou e disse: "você é muito tranqüila pra resolver as coisas, sinto confiança quando você está por perto". A mãe comentou que quando elas tentaram sair juntas, Lua "dava muito trabalho", desistiam sempre na porta do lugar. Desta forma, Colhendo alguns frutos, foi a frase representativa deste encontro.

Logo de início foi clara a melhora na auto-estima da usuária que se arrumara para o encontro, mostrando-o a importância que dava para a imagem, estar bonita.

O AT proporcionou uma vitória para Lua no enfrentamento de um desafio. Assim ela pôde ver como pode ser recompensadora essa luta contra as dificuldades. O momento de descontração junto à mãe contribuiu para uma reaproximação, no entanto nem sempre seria assim.

O relacionamento é de pessoa para pessoa, com afetividade, bondade, respeito, responsabilidade e liberdade. A liberdade permite a pessoa um vasto horizonte para pensar e sentir. Livre para suportar as conseqüências dos seus erros e também dos seus esforços positivos, esse tipo de liberdade faz com que a pessoa seja ela mesma ${ }^{(11)}$.

No nono encontro, Lua revela: "O que aconteceu foi que fui me envolvendo cada vez mais com aquelas pessoas, conhecendo outras pessoas até que, por fim, já era garota de programa. Eu adorava! Era linda, era perfeita, tinha cabelos cacheados, alta, olhos verdes, todos ficavam loucos comigo. Só pegava homens ricos, bonitos, podia escolher. Ganhava jóias, sapatos e roupas de marca, tudo caríssimo, fora a grana que me pagavam. Saía com pessoas importantíssimas da alta sociedade, vários quiseram namorar comigo, pra que eu ficasse só com eles, ter uma vida normal. Mas eu gostava daquilo, do meu sucesso, do sexo, deles se jogando aos meus pés". Lua continuou: "minha vida acabou, eu era 'glamourosa', linda, perfeita e, agora, não tenho nada. Só esse quarto onde durmo e como o dia todo". A análise da síntese do encontro levou a seguinte frase representativa: Segredos do passado e não aceitação do presente.

Lua dá uma mostra de confiança na pessoa do at ao contar segredos do passado de evidente gravidade, mas assume um tom de desencanto com o presente. Tal confiança abre portas para que o at 
insista em não deixar que o desânimo tome conta e que Lua tenha uma recaída. Reagindo de forma humana (não esquecendo o alicerce do AT), percebi que Lua estava tendo uma recaída ao pensar na perda do sentido de sua vida sem aquilo que ela chamava de "glamour", então confrontei (emprestando o ego) aquela idéia tentando fazê-la pensar a respeito da aceitação da perda daqueles valores para tentar, assim, achar novos valores para sua nova vida.

Normalmente o transtorno mental não absorve todos os aspectos da vida da pessoa, atingindo, apenas, algumas funções de sua vida mental, o que permite conservar a consciência de si mesmo, do mundo e do que faz, embora possa estar, por vezes, desorientado. Com a consciência de si mesmo, do mundo e daquilo que faz, o portador de transtorno mental é capaz de desencadear e vivenciar um estresse muito grande ao ter a noção de seu real estado, que resultam em impotência e vulnerabilidade em não poder vencer tal transtorno. Esta fragilidade aparece muitas vezes, no descontrole da situação, assumindo a forma de tristeza, irritação, confusão e instabilidade emocional ${ }^{(16)}$.

No décimo encontro, fomos para o quintal tomar ar. Ventava de forma agradável e ela pareceu ler meu pensamento, pois disse: "tá tão gostoso, um vento bom". Ficamos ali, sentadas em silêncio por uns vinte minutos, os cachorros começaram a pular no colo dela num clima ótimo e ela falou: "é muito bom ter a sua companhia. Estava triste e apareceu um ânimo, lá do fundo, pra eu aguentar mais um pouco essa vida"; "aprender braile, andar de bengala esbarrando num monte de cegos"; "tá tão gostoso, um vento bom"; "Vou pensar com carinho". E essa manifestação de Lua tornou-se a frase representativa deste encontro: Vou pensar com carinho.

A presença do at tem tamanho significado para a usuária que esse estar presente basta para que ela consiga sair de um estado de agonia, recobrando a calma, e, refletindo, considerar uma possibilidade que antes rechaçara.

O encontro foi integrador porque o sujeito está sendo acompanhado por um corpo simbólico, momentos em que simplesmente estamos ali, junto da pessoa, onde, não há o que fazer ou dizer, nossa presença, já significa bastante ao acompanhado (função holding) $^{(6)}$.

No décimo primeiro encontro, na casa de Lua, falou-se de alguns prazeres e provável ocupação: “A comida é muito boa, não consigo parar", afirmou. "Mas, eu gosto de comer, é um dos poucos prazeres que me restam e não abro mão!", comentou. "E quais são os outros prazeres?" quis eu saber. "Falar no telefone e dormir. Mais nada", respondeu. "Você não gostaria de ter um trabalho, que fique falando ao telefone, tipo telemarketing?" "Sim, mas sou aposentada, não posso ser registrada e eles não contratam sem registrar". "Sei lá, e um trabalho voluntário, uma ou duas vezes por semana, atendimento ao cliente, CVV (Centro de Valorização da Vida)?". Isso levou a seguinte frase representativa deste encontro: Ansiedade, ócio e comida.

Lua é extremamente ansiosa e, vivendo de forma ociosa, ficando em casa o tempo todo, depositava essa ansiedade na comida, o que causava outros vários problemas. Talvez uma ocupação, fazendo-a se sentir útil poderia ajudar. No entanto, pareceu que ela não se animou muito com a idéia.

No décimo segundo encontro Lua disse que estava bem, havia pensado no emprego ou trabalho voluntário, seria bom, já trabalhara em algo parecido, tinha habilidade para aquilo. Podia ter mudado fisicamente, mas a voz continuava a mesma. Pediu que eu a ajudasse a arrumar um trabalho do tipo. "Tudo bem", falei, "mas acho que vai ter que ser algo voluntário já que não pode ser registrada".

Lua continuou: "Mudando de assunto, fui a um médico que disse ser viável uma cirurgia de estômago pra tratar minha obesidade, o que você acha?". "É uma boa opção, mas tem que se preparar, falar com outros médicos, com um psicólogo...". Assim, estabelecemos como frase representativa do encontro: Mais realidade é igual a mais mudança.

Cada vez mais Lua parecia defrontar-se com as possíveis mudanças e com o fato de que isso requeria a aceitação de sua vida como realmente era nesse momento.

Lua começou o décimo terceiro encontro dizendo: "estou muito confusa, só de imaginar que vou fazer esta cirurgia e vou poder usar minhas calças novamente, ter o corpo que tinha antes, usar meus tênis, mas ao mesmo tempo comer é a única alegria que tenho, mas também minha vida pode mudar, estou com medo dessas mudanças".

Expliquei à Lua que havia um longo caminho a ser percorrido antes da cirurgia, ela precisava se acalmar, tudo era uma hipótese e tínhamos que fazer todos os testes, passar por avaliações médicas, exames, psicólogo, psiquiatra e, só então, seria avaliado se ela poderia ou não passar por este tipo de cirurgia.

Lua respondeu: "você tem razão, eu fantasio muito, nem sei se vou poder fazer essa cirurgia, vou pensar na minha viagem e apenas pesquisar sobre o assunto, procurar um médico quando eu voltar... aí veremos as possibilidades. Eu preciso olhar minha vida de outra forma". A frase representativa deste encontro foi: Moderar a impulsividade para não perder o foco.

A possibilidade da cirurgia de estômago havia empolgado tanto Lua a ponto de achar que havia encontrado aquela mágica com a qual sonhava para ter sua antiga vida de volta. O at agiu de forma a moderar esse deslumbramento chamando a usuária 
de volta para o mundo onde aquela vida passada não tinha mais lugar, sem excluir a possibilidade da cirurgia que, se adequada, poderia ser benéfica.

No décimo quarto encontro, Lua se manifesta: "Já estou decidida. Vou fazer essa cirurgia do estômago. Será melhor, vou ficar bem de saúde, poderei usar meus tênis All-Star, minha calça Saint Tropez, terei meu corpo de volta, vou poder sair novamente freqüentar os lugares que eu ia, fazer amigos e ter uma vida saudável. O que você acha?". "Lua, eu acho que essa cirurgia seria muito boa para sua saúde, mas você está criando muitas expectativas. Ainda não sabemos se você pode fazer, vamos com calma, não quero te desanimar, mas o processo desta cirurgia é muito complicado, vamos primeiro uma palestra sobre isso no Hospital das Clínicas, vou ver o dia e o horário". Assim, a frase representativa do encontro foi: Cirurgia: obsessão a ser desmistificada.

Nesse encontro foi importante a presença do at, pois suas expectativas eram grandes e a frustração poderia ser maior, então foi enfatizado para ela, o tempo todo, que a cirurgia talvez não fosse adequada no seu caso. O at, aqui, emprestou o ego a ela para moderar aquele desejo, ponderando os possíveis efeitos negativos para os quais ela fechara os olhos.

Nesse momento foi muito importante emprestar o ego, assim funcionou como um espelho dos seus aspectos mais neuróticos, desta forma conseguindo uma linguagem libertadora saindo de sua clausura e abrindo-se para novas reflexões ${ }^{(6)}$

Para o décimo quinto encontro foi proposta uma ida ao Hospital das Clínicas para assistir a palestra sobre a cirurgia de estômago, e, terminada a palestra, fomos saindo quando Lua disse: "não vou fazer esta cirurgia, não é pelo procedimento, mas ficou bem claro o pós-cirúrgico, foi bem o que você disse para aquela senhora na discussão, se eu sou ansiosa vou querer comer outras coisas como, leite condensado, sorvete, tomar cerveja... esses são alimentos que passam fácil pelo estômago e aí toda cirurgia se perde, então prefiro me controlar com uma dieta alimentar e tratar meus problemas psicológicos e transtornos mentais e, quem sabe, depois faço a cirurgia". A frase representativa deste encontro foi: Não há mágica, mas a dedicação e o esforço.

A proposta do at de conhecer melhor o processo da cirurgia, indo à palestra com Lua, foi fundamental para que ela tomasse consciência de que até mesmo aquele procedimento demandava vários sacrifícios e, acima de tudo, o fato de Lua não ser apta, devido aos transtornos que apresentava, mostrou-lhe quantos problemas ela tinha que enfrentar antes de qualquer coisa.

No décimo sexto e último encontro, quando cheguei, Lua me esperava na sala, toda sorridente e feliz porque perdera quatro quilos em duas semanas.
Comentei que era muito difícil perder tanto peso em tão pouco tempo. Ela disse: “Eu fiz a dieta direitinho, tenho facilidade para perder peso e espero continuar assim, perdendo dois quilos toda semana". Falei que no começo da dieta é mais fácil, a gente emagrece bastante e depois vai ficando mais difícil, mas tinha certeza de que ela conseguiria.

Reafirmei a importância de participar dos programas do CAPS. Seria importante dar seguimento aos encontros no grupo de auto-ajuda oferecido pela AAPSI, pois no dia anterior eu havia acompanhado Lua e a família até a reunião para mostrar como funcionava. Não fiquei com ela na reunião e queria saber o que tinha achado. Lua havia gostado, achou o pessoal receptivo fez várias amizades e realmente pretendia continuar indo aos encontros. A mãe e o avô, que ficaram comigo na outra sala, onde acontece a reunião dos familiares, se soltaram, falaram bastante sobre os problemas da casa, com Lua, e foram muito bem acolhidos pelos outros participantes, saíram elogiando e dizendo que voltariam todas as semanas. Assim, a frase representativa do último encontro foi: Continuidade e perseverança.

O AT tem a oportunidade de intervir para auxiliar o acompanhado a ampliar a sua consciência a respeito de si e do mundo ${ }^{(6)}$.

Com isso, foi possível entender que ao longo de todos esses encontros Lua não deixou de expressar o sentimento da necessidade de um eterno enfrentamento com o qual tinha que lidar a partir da situação que tanto a marcou. Mesmo nos momentos mais difíceis, quando as palavras representativas dessas necessidades, não eram totalmente articuladas, percebia-se que eram ditas em forma de símbolos, e, examinadas em profundidade, mostravam seu grande significado, abrindo totalmente as portas para o AT.

As frases representativas de cada um dos encontros de AT realizados podem ser também consideradas significativas, pois exprimem o conteúdo de cada um dos referidos encontros. Tal afirmação é possível pelo cuidado dispensado na elaboração das mesmas. As sínteses dos encontros, além de serem examinadas por dois examinadores com experiência na Área da Saúde Mental, foram também examinadas por um terceiro, leigo no tema, na busca da fidelidade da síntese final. Examinando o grupo das frases, é possível perceber uma grande coerência entre elas, já partindo da primeira, onde é estabelecido um contrato, que é imprescindível não somente para a assistência através do AT, mas em qualquer modalidade de assistência psiquiátrica.

A presença do at trouxe possibilidades de resgate a diversas rotinas da vida de Lua, e, daí, o aparecimento do sentimento de prazer. O prazer frente às possibilidades de fazer coisas, de se ocupar. Vem seqüencialmente um quadro aparentemente 
confuso, ou mesmo dissociado, mas lógico dentro do contexto, pois um retorno a uma idade pueril, ingênua, tem extrema relação com a felicidade, vivida em idades iniciais da vida.

Posteriormente, há uma visão voltada para si, uma projeção interna, e logo o pensamento na mudança. Há o contato com a realidade, inclusive uma crítica, pois a mudança não se constitui em algo fácil de ser realizado, trata-se de alguma coisa que demanda de longo tempo, uma intensa busca com o envolvimento de estruturas internas muito enraizadas através do tempo e que para serem trabalhadas precisam, antes, estarem expostas a todo o processo de trabalho que se oferece para isso, no caso, o AT.

Lua esteve exposta ao AT. Com suas dificuldades, facilidades e disposições. Apresentou todo o seu lado emotivo e depositou uma grande confiança no at, o que pode ser considerado um ponto importantíssimo no presente estudo, onde o cliente deposita total confiança no terapeuta. É também fundamental destacar o momento em que isso ocorre. Foi exatamente na metade do tempo proposto para sua assistência, o que leva ao entendimento de que Lua queria continuar a ser assistida pelo at, e, provavelmente, se expor mais, na busca de uma forma para conviver com a sua nova realidade.

Isso de certa forma é revelado por Lua no momento em que ela, na sua reflexão, expressa a dificuldade em reaprender, mas que a possibilidade estava em seu pensamento. A presença da ansiedade, e, com isso, a busca de uma alimentação bem acima da sua necessidade, reflete o seu momento provavelmente de luta e fuga, pois viver uma realidade, que nesse momento não era a dela, implicava em mais adequações, incluindo que não havia algo mágico salvador, mas sim um esforço seu para alcançar o objetivo de viver melhor, e, daí, a importância em continuar.

E, assim, Lua viveu por um período de quatro meses esse processo de AT, que se tratou de um período relativamente curto para uma tão esperada mudança. É necessário destacar que provavelmente demorará alguns anos para ocorrer, pois se trata não apenas de sua situação pós-acidente, mas de uma situação de vida, observando que sua personalidade não foi constituída a partir da sua nova situação, mas sim, desde o início da sua existência.

Então, o AT certamente teve uma importância ímpar nesse momento da vida de Lua, pois se pode imaginar que ela, vivendo todo um processo de luta e fuga, estava lutando ou fugindo não apenas para se manter ou abandonar as atividades do AT, mas sim em todos os aspectos, incluindo a vida.

\section{CONSI DERAÇÕES FI NAIS}

Mostrar a contribuição do AT no processo de assistência e reabilitação psicossocial do portador de transtorno mental se constituiu no objetivo do presente estudo. Por tudo o que foi descrito, fica claro o grande valor desta modalidade terapêutica, inserida totalmente no contexto da Reforma Psiquiátrica, onde há a previsão de associações de modalidades terapêuticas na grande busca do real controle dos sintomas das psicopatologias e também da reintegração dos portadores de transtornos mentais na sociedade. Assim sendo, o AT mostrou uma contribuição altamente positiva, tanto na assistência, quanto na reabilitação psicossocial do portador de transtorno mental, que pôde ser observado nos seguintes aspectos: resgate de sua auto-estima; retomada da realização de atividades que fazia anteriormente ao início dos sintomas de seu transtorno mental; motivação para novamente buscar o laser e conviver de forma mais saudável no seu meio familiar e social; criação de momentos de confronto de seu estado mental com a realidade, possibilitando modificações no comportamento e melhoria da qualidade de vida.

Assim sendo, foi possível considerar que o AT constitui-se em mais uma modalidade terapêutica a contribuir para a assistência e reabilitação psicossocial do portador de transtorno mental e pode ser incluído nos planos terapêuticos dos serviços de assistência à saúde mental, pois se trata de uma modalidade terapêutica não tradicional, totalmente inserida no contexto da reforma psiquiátrica e que tem como princípio básico a mudança no foco da assistência aos portadores de transtornos mentais.

O AT com sua abordagem não tradicional de aproximação entre acompanhante e acompanhado, através de um vínculo que se formou (não esquecendo a importância da realização do trabalho em conjunto com os tratamentos tradicionais) criou novas possibilidades terapêuticas, frutos dessa vivência próxima, a partir de situações cotidianas, que proporcionou resultados positivos quanto à evolução do quadro, levando, em diferentes níveis, à mudança de comportamento, melhoria da qualidade de vida, reabilitação psicossocial e melhoria nas relações familiares.

O presente estudo, pela exposição dos encontros analisados, cumpre sua função de atentar para a importância da prática do AT no processo de assistência e reabilitação psicossocial dos usuários dos serviços de saúde mental, notoriamente neste momento histórico de reavaliação metodológica desse processo, decorrente dos questionamentos feitos pelo Movimento da Reforma Psiquiátrica. A prática do AT e seus resultados são mais um elemento a corroborar uma mudança no foco do tratamento de portadores de transtornos mentais prenunciando o fim de um tempo, o fim do 
manicômio como prisão, o fim do uso cômodo dos medicamentos e do confinamento. Urge lançarmos mão dessas formas não tradicionais de assistência aos portadores de transtornos mentais, reconhecendo seu valor.

A prática do AT deve ser incentivada e patrocinada, pois o contato humano é a via da transformação.

O caso aqui apresentado é testemunho de como tal contato é impactante. Em momentos conflituosos a presença fraterna consciente e cheia de significação do at influiu na formação dessa nova pessoa a qual busca a usuária participante do estudo; a qual buscamos dia após dia. Solucionar, superar problemas, às vezes aparentemente tão simples, se tornavam desafios extremos para ela e só outra presença humana preparada seria capaz de ajudá-la a desatar esses nós.

Importante destacar o fato de que o AT deve persistir pelo tempo necessário até que o portador de transtorno mental readquira sua autonomia. No presente estudo, foram utilizados dezesseis encontros de AT, considerados suficientes para os seus propósitos e isso se mostrou adequado, visto que, os conteúdos dos encontros apontaram para uma contribuição positiva do AT desde o seu início. Destaca-se ainda, que, no caso de Lua, frente sua complexidade, seriam necessários à utilização do AT durante um período bem maior de tempo, ou, seja, uma assistência através desta modalidade terapêutica por longo prazo, incluindo avaliações periódicas. Então, deve haver atenção especial no sentido desta modalidade terapêutica não se transformar em mais uma forma de escapismo. Para tanto, é fundamental que o profissional (e isso é fruto da qualificação e seriedade deste) não tome decisões pelo usuário ao qual presta a assistência, a não ser em determinadas situações-limite, mas seja um estímulo norteador nas resoluções dos conflitos vividos por esse usuário fomentando sua independência.

O trabalho junto à equipe foi de grande importância, pois a mesma possibilitou a discussão do caso e o enfrentamento de situações difíceis para o at. O respeito pelo trabalho do AT foi de suma importância, pois em lugar de qualquer tipo de imposição houve discussão e sugestão valorizando a autonomia do AT como parte de um grupo.

\section{REFERÊNCIAS}

1. Carvalho SS. Acompanhamento Terapêutico: que clinica é essa? 1st ed. São Paulo: Annablume; 2004.

2. Ayub P. Do amigo qualificado ao acompanhante terapêutico. Infanto - Rev. Neuropsiq. da Inf. e Adol. 1996; 4(2): 37-40.

3. Bertolote JM. Em busca de uma identidade para a reabilitação psicossocial. In: Pitta A, org. Reabilitação psicossocial no Brasil. São Paulo: Hucitec; 1996. p. 155-8.

4. Santos SA. Projeto terapêutico individual em um Centro de Atenção Psicossocial: o conhecimento do usuário e contribuições na assistência [thesis]. Ribeirão Preto: Escola de Enfermagem/USP; 2006.

5. Pitiá ACA, Santos MA. Acompanhamento Terapêutico: a construção de uma estratégia clínica. 1st ed. São Paulo: Vetor Editora; 2005.

6. Barreto KD. Ética e técnica no acompanhamento terapêutico: andanças com Dom Quixote e Sancho Pança. 2st ed. São Paulo: Unimarco; 2000.

7. Farinha MG. Acompanhamento terapêutico como estratégia de inserção da pessoa em sofrimento psíquico na comunidade: estudo em um programa de saúde da família [thesis]. Ribeirão Preto: Escola de Enfermagem/USP; 2006. 34 p.

8. Piszezman MLRM. Terapia familiar breve: uma nova abordagem terapêutica em instituições. 2 st ed. São Paulo: Casa do Psicólogo; 2007.

9. Moreno JL. Psicodrama. 1st ed. Buenos Aires: Hormé; 1961.

10. Waldow VR. Cuidado: uma revisão teórica. Rev. gaúcha enferm. 1992;13(2):29-35.

11. Rogers CR. Tornar-se pessoa. 5st ed. São Paulo: Martins Fontes; 2001.

12. Minayo MC. O desafio do conhecimento. Pesquisa qualitativa em saúde. 8st ed. São Paulo: HucitecAbrasco; 2004.

13. Rudio FV. Orientação não diretiva: na educação, no aconselhamento e na psicoterapia. 14st ed. Petrópolis: Vozes; 2003.

14. Fernández A. A inteligência aprisionada. 1st ed. Porto Alegre: Artmed; 1991.

15. Avanci RC, Furegato ARF, Scatena MCM, Pedrão LJ. Relação de ajuda enfermeiro-paciente póstentativa de suicídio. SMAD: Rev. Eletr. Álcool Drogas. [Internet]. 2009 [cited 2010 mar 15];5(1). Available from:

http://www2.eerp.usp.br/resmad/artigos/2009v5n1 $\% 2005 . p d f$.

16. Moraski TR., Hildebrandt LM. As percepções de doença mental na ótica de familiares de pessoas psicóticas. Rev. Eletr. Enf. [Internet]. 2005 [cited 2010 mar 15];7(2):195-206. Available from: http://www.fen.ufg.br/revista/revista7_2/original_08.htm.

Artigo recebido em 28.10.08.

Aprovado para publicação em 29.10.09.

Artigo publicado em 31.03.10. 